\title{
Do we use the appropriate controls for the identification of informative methylation markers for early cancer detection? Yasser Riazalhosseini and Jörg D Hoheisel
}

\begin{abstract}
Address: Functional Genome Analysis, Deutsches Krebsforschungszentrum, Im Neuenheimer Feld 580, 69120 Heidelberg, Germany.
\end{abstract}
Correspondence: Yasser Riazalhosseini. Email: y.riazalhosseini@dkfz.de

Published: 26 November 2008

Genome Biology 2008, 9:405 (doi: I0.I I86/gb-2008-9-II-405)

The electronic version of this article is the complete one and can be found online at http://genomebiology.com/2008/9/I I/405

(C) 2008 BioMed Central Ltd

\begin{abstract}
It is possible to miss potential DNA methylation markers of tumorigenesis because of the initial filtering of profiling results on the basis of inappropriate controls.
\end{abstract}

Epigenetic programming - the variation of the chemical modifications of both histones and DNA - dictates the interpretation of the genetic code. For example, different cell types can be distinguished by their, at least partly, distinct epigenetic status. Similarly, tumor cells exhibit epigenetic patterns that vary from those of normal cells. These differences in epigenetic programming cause concomitant differences in gene-expression patterns.

DNA methylation is the best-studied epigenetic marker. In the human genome, DNA methylation occurs at cytosines that are located 5' to guanines, known as $\mathrm{CpG}$ dinucleotides. Abnormal changes in methylation patterns found in human cancers include global demethylation of DNA with simultaneous hypermethylation of $\mathrm{CpG}$-rich regions called $\mathrm{CpG}$ islands. These islands occur in promoter regions of many tumor suppressor genes and are usually not methylated in normal cells $[1,2]$. Because aberrant DNA-methylation events are both stable and abundant in tumors and also occur in the early stages of tumorigenesis, detection of hypermethylated DNA is considered a most promising tool for the diagnosis of cancer. Specialized microarrays, mass spectrometry and - more recently - ultrahigh-throughput sequencing procedures provide an opportunity for comprehensive DNAmethylation profiling of human cancers with the eventual aim of identifying selective markers for early detection $[3,4]$.

Including appropriate control (cancerfree) samples in the analysis is essential for the identification of true markers. In solid tumors, cancer-free tissue found adjacent to the actual tumor, as well as normal tissues of the same tissue type from healthy individuals, are conceivable controls. The former are extensively used as controls in many laboratories for the exclusion of methylation patterns induced by factors such as environmental influences or aging (see for example [5-7]). The logic of this is based on the assumption that cancer-associated methylation alterations would not have occurred in the adjacent, apparently normal tissue. However, this assumption has been challenged by recent reports that identify altered DNA methylation in preneoplastic lesions associated with different tumor types, including breast cancers [8-10].
Examining normal breast cells from healthy individuals and cells from breast tumors, Yan et al. [10] found hypermethylated loci in breast tumors that showed no or low methylation in normal individuals. Notably, these loci were also frequently hypermethylated in normal tissues adjacent to the tumors. Hypermethylation of tumor suppressor genes has also been reported in women who are at risk of developing breast cancer but who do not have cancer. This abnormal change occurs more frequently in benign breast epithelium (that is, epithelium with non-malignant changes) of women at high risk for breast cancer than in people at low risk $[8,11]$. Strikingly, abnormally methylated DNA has even been identified in mammary epithelial cells with normal morphology in highrisk women [12]. Moreover, a possible seminal role for epigenetic abnormalities in the earliest steps of cancer initiation has been emphasized [13,14].

In combination, these findings suggest a possible cancer-predisposing role for DNA methylation and support the emerging evidence for an involvement of aberrant DNA-methylation patterns 


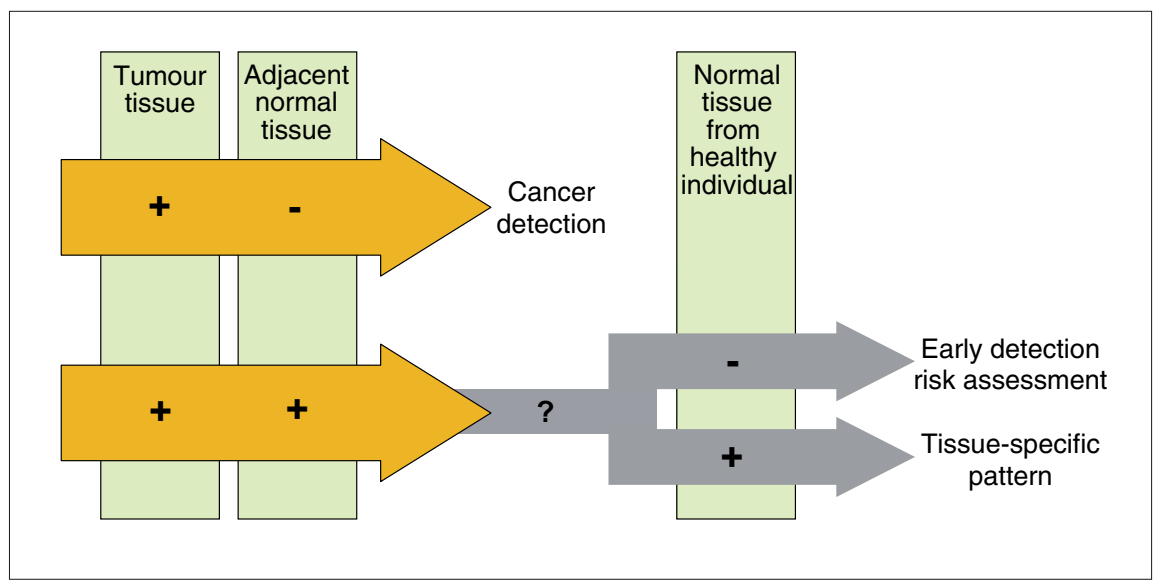

Figure I

Schematic presentation of the possible variations in the DNA methylation status of a genomic locus and the conclusions that could be drawn from this information. Plus and minus signs indicate hyperand hypomethylation, respectively.

in the proposed 'field defect' (or 'field cancerization') concept [15-17]. It is becoming clear that hypermethylation of DNA in normal-appearing tissue located adjacent to tumors is more prevalent than previously recognized. Early cancerassociated methylation patterns might also have occurred in these tissues. Therefore, the epigenetic pattern would not be distinguishable between cancer samples and such a control (Figure 1). In consequence, using patient-matched normal tissues from regions adjacent to the actual tumor as the sole control is probably insufficient for the identification and selection of methylation markers for early cancer detection, although these control samples could be helpful in finding prognostic or predictive biomarkers.

A practical example of such an early alteration is hypermethylation of the gene $S F N$ in breast cancer. While this gene is hypermethylated in breast tumors and adjacent normal tissues, the breast epithelium from cancer-free individuals contains unmethylated $S F N$ DNA. However, $S F N$ methylation was not identified as a potential marker in a recent comprehensive genome-wide methylation analysis, because the initial filtering was referenced only to the tissues adjacent to the tumors in cancer patients $[6,18,19]$. One cannot entirely exclude the possibility that factors related to the array-analysis platform, such as assay sensitivity, might have contributed to the result. This is very unlikely, however.

DNA-methylation patterns associated with cancer development have been recognized for their potential in clinical use. They are under study as diagnostic markers, prognostic factors and predictors of responses to treatment. In addition, a human epigenome project has been launched to map all epigenetic patterns in normal and affected cells $[2,3,20]$. The methods and processes are at hand for specific and sensitive screening approaches to aid DNA marker identification. In this Correspondence, we picked breast cancer for in-depth discussion. However, the points raised are likely to be valid for other types of tumors. For all these, the addition of appropriate cancer-free control materials to the screening panels might help in the identification of truly informative markers and would avoid missing DNA-methylation markers for early detection and risk assessment.

\section{References}

I. Jones PA, Baylin SB: The epigenomics of cancer. Cell 2007, I28:683-692.

2. Esteller M: Epigenetics in cancer. $N$ Engl J Med 2008, 358: I I 48-I I 59.
3. Gal-Yam EN, Saito Y, Egger G, Jones PA: Cancer epigenetics: modifications, screening, and therapy. Annu Rev Med 2008, 59:267-280.

4. Hoheisel JD: Microarray technology: beyond transcript profiling and genotype analysis. Nat Rev Genet 2006, 7:200-2I0.

5. Shames DS, Girard L, Gao B, Sato M, Lewis $C M$, Shivapurkar N, Jiang A, Perou CM, Kim $Y H$, Pollack JR, Fong $K M$, Lam $C L$, Wong M, Shyr Y, Nanda R, Olopade OI, Gerald W, Euhus DM, Shay JW, Gazdar AF, Minna JD: A genome-wide screen for promoter methylation in lung cancer identifies novel methylation markers for multiple malignancies. PLoS Med 2006, 3:e486.

6. Ordway JM, Budiman MA, Korshunova $Y$ Maloney RK, Bedell JA, Citek RW, Bacher B, Peterson S, Rohlfing T, Hall J, Brown R, Lakey N, Doerge RW, Martienssen RA, Leon J, McPherson JD, Jeddeloh JA: Identification of novel high-frequency DNA methylation changes in breast cancer. PLOS ONE 2007, 2:el 3 | 4.

7. Chung $W$, Kwabi-Addo B, Ittmann $M$, Jelinek J, Shen L, Yu Y, Issa JP: Identification of novel tumor markers in prostate, colon and breast cancer by unbiased methylation profiling. PLOS ONE 2008, 3:e2079.

8. Lewis CM, Cler LR, Bu DW, ZochbauerMuller S, Milchgrub S, Naftalis EZ, Leitch AM, Minna JD, Euhus DM: Promoter hypermethylation in benign breast epithelium in relation to predicted breast cancer risk Clin Cancer Res 2005, II: I66-I72.

9. Holst CR, Nuovo GJ, Esteller M, Chew K, Baylin SB, Herman JG, Tlsty TD: Methylation of pl6(INK4a) promoters occurs in vivo in histologically normal human mammary epithelia. Cancer Res 2003. 63:1596-1601.

10. Yan PS, Venkataramu C, Ibrahim A, Liu JC, Shen RZ, Diaz NM, Centeno B, Weber F, Leu YW, Shapiro CL, Eng C, Yeatman T], Huang TH: Mapping geographic zones of cancer risk with epigenetic biomarkers in normal breast tissue. Clin Cancer Res 2006, 12:6626-6636.

II. Euhus DM, Bu D, Milchgrub S, Xie XJ, Bian A, Leitch AM, Lewis CM: DNA methylation in benign breast epithelium in relation to age and breast cancer risk. Cancer Epidemiol Biomarkers Prev 2008, I7:10511059.

12. Bean GR, Bryson AD, Pilie PG, Goldenberg V, Baker JC Jr, Ibarra C, Brander DM, Paisie C, Case NR, Gauthier M, Reynolds PA, Dietze E, Ostrander J, Scott V, Wilke LG, Yee L, Kimler BF, Fabian CJ, Zalles CM, Broadwater G, Tlsty TD, Seewaldt VL: Morphologically normal-appearing mammary epithelial cells obtained from high-risk women exhibit methylation silencing of INK4a/ARF. Clin Cancer Res 2007, |3:6834-684I.

13. Baylin SB, Ohm JE: Epigenetic gene silencing in cancer - a mechanism for early oncogenic pathway addiction? Nat Rev Cancer 2006, 6: 107-II6.

14. Feinberg AP, Ohlsson R, Henikoff S: The epigenetic progenitor origin of human cancer. Nat Rev Genet 2006, 7:21-33.

15. Giovannucci E, Ogino S: DNA methylation, field effects, and colorectal cancer. J Natl Cancer Inst 2005, 97:1317-1319.

16. Shen L, Kondo Y, Rosner GL, Xiao L, Hernandez NS, Vilaythong J, Houlihan PS, 
Krouse RS, Prasad AR, Einspahr JG, Buckmeier J, Alberts DS, Hamilton SR, Issa JP: MGMT promoter methylation and field defect in sporadic colorectal cancer. J Natl Cancer Inst 2005, 97:1330-1338.

17. Liang G, Wolff EM, Chihara Y, Pan F, Weisenberger $D$, Laird PW, Jones PA: DNA methylation profile of $150 \mid$ loci in bladder cancer shows evidence of a field defect. In Proc 99th Annual Meeting Am Ass Cancer Res: 12-16 April 2008; San Diego. 2008: Abstract 2625.

18. Ferguson AT, Evron E, Umbricht CB, Pandita TK, Chan TA, Hermeking H, Marks JR, Lambers AR, Futreal PA, Stampfer MR, Sukumar S: High frequency of hypermethylation at the 14-3-3 sigma locus leads to gene silencing in breast cancer. Proc Natl Acad Sci USA 2000, 97:6049-6054.

19. Umbricht $C B$, Evron E, Gabrielson E, Ferguson A, Marks J, Sukumar S: Hypermethylation of 14-3-3 sigma (stratifin) is an early event in breast cancer. Oncogene $200 \mathrm{I}$, 20:3348-3353.

20. Jones PA, Martienssen R: A blueprint for a human epigenome project: the AACR Human Epigenome Workshop. Cancer Res 2005, 65: | | 24|-I | 246. 